\title{
SARS-CoV-2 and Systemic Lupus Erythematosus
}

\author{
Aikaterini Thanou ${ }^{1}$ (D) - Amr H. Sawalha ${ }^{2}$ (D) \\ Accepted: 8 December 2020 / Published online: 28 January 2021 \\ (C) The Author(s), under exclusive licence to Springer Science+Business Media, LLC part of Springer Nature 2021
}

\begin{abstract}
Purpose of Review To summarize current knowledge of the impact of coronavirus disease 19 (COVID-19) on patients with systemic lupus erythematosus (SLE).

Recent Findings Several observational studies, including case series, patient surveys, and patient registries, have examined the incidence and severity of COVID-19 in patients with SLE. Due to methodologic limitations (focus on sicker patients, exclusion of asymptomatic or mild cases, limited or inaccurate viral testing), it is difficult to determine the risk and outcomes of COVID-19 in SLE patients. Corticosteroids might be associated with increased hospitalizations from COVID-19 in individuals with autoimmune rheumatic diseases. Some immune suppressive treatments do not appear to significantly increase the risk of contracting COVID-19 or poor subsequent outcomes; however, data on the safety of specific drugs remain scarce. Studies in nonautoimmune cohorts have shown more severe COVID-19 in ethnic and racial minorities, populations also more heavily impacted by SLE. Such results have been attributed to highly prevalent socioeconomic disparities and comorbidities. The complex interplay between SARS-CoV-2 and the host immunologic milieu may have particular implications for patients with SLE that remain to be explored. Concerns have been raised of COVID-19 heightening the risk of thromboembolic events in the presence of an SLE-induced procoagulant state.

Summary Limitations in epidemiologic data available to date do not allow for assessing the risk and severity of COVID-19 in patients with SLE. Other than corticosteroids, prior use of some immune suppressive medications does not appear to increase the risk for infection with SARS-CoV-2 however, more comprehensive studies are needed.
\end{abstract}

Keywords Systemic lupus erythematosus · COVID-19 · Immunosuppression

\section{Introduction}

Systemic lupus erythematosus (SLE) is a multisystem autoimmune disease with protean manifestations and a chronic fluc-

This article is part of the Topical Collection on Systemic Lupus Erythematosus

Aikaterini Thanou

aikaterini-thanou@omrf.org

Amr H. Sawalha

asawalha@pitt.edu

1 Arthritis and Clinical Rheumatology Program, Oklahoma Medical Research Foundation, 825 NE 13th Street, MS 22, Oklahoma City, OK 73104, USA

2 Departments of Pediatrics, Medicine, and Immunology, and Lupus Center of Excellence, University of Pittsburgh School of Medicine, 7123 Rangos Research Center, 4401 Penn Avenue, Pittsburgh, PA 15224, USA tuating clinical course [1]. The emergence and rapid global spread of the coronavirus-associated disease 19 (COVID-19) pandemic has raised multiple questions for rheumatologists about infection risk and the proper use of immune suppressive medications by patients with SLE and other chronic autoimmune rheumatic diseases (AIRDs) [2]. Individuals with SLE might be at increased risk for contracting SARS-CoV-2 and a more severe clinical course once infected, due to SLE-related innate immune perturbations and increased baseline inflammation [3]. Immune suppressive medications are associated with increased infections, while they may also dampen exuberant immune responses seen in severe COVID-19. Social determinants of health and comorbidities prevalent in SLE cohorts have been independently associated with COVID-19 in other populations $[4,5]$. While the pandemic evolves, research on the impact of COVID-19 in patients with SLE and other autoimmune diseases has been ongoing, providing preliminary evidence to assist clinical decision-making and generate hypotheses to be tested. 


\section{COVID-19: Immunopathologic and Clinical Highlights}

SARS-CoV-2 is a novel RNA coronavirus of the same family as SARS-CoV and Middle East respiratory syndrome coronavirus that mainly spreads through the respiratory tract [6]. SARS-CoV-2 enters cells by binding to the angiotensin converting enzyme 2 (ACE2) receptor [7] suggesting that factors enhancing ACE2 expression could increase viral entry and COVID-19 susceptibility. Infection can be mild or asymptomatic in up to $80-90 \%$ of infected individuals, and clinical disease mainly manifests with systemic and respiratory symptoms that range from mild to severe [8].

Both innate and adaptive immune mechanisms are involved in the early immune response against SARS-CoV-2 [6]. Macrophages, neutrophils, and dendritic cells appear important in early defense, the latter cells being the main inducers of an early type I interferon (IFN) response at the infection site that limits viral replication and systemic immune activation. Both the robustness and timing of this response are considered critical in COVID-19, with delayed or low responses resulting in elevated lung cytokine/chemokine levels, impaired virus-specific $\mathrm{T}$ cell responses, and late clinical deterioration [9॰]. Cytotoxic CD8 T cell responses emerge in the next few days, and are impaired in severe COVID-19, but when robust, can control COVID-19 and lead to viral elimination. Antibody responses are generated within 12-14 days of infection, and might be protective against future infection or reinfection, although B cells and immune globulins are probably not obligate for a protective immune response to SARS-CoV-2 [10].

A small minority (5\%) of patients with COVID-19 pneumonia show sudden rapid clinical deterioration late in the disease course, despite declining levels of SARS-CoV-2 viral load. These patients progress to acute respiratory distress syndrome (ARDS) and a systemic cytokine storm associated with considerable mortality $[9 \bullet, 11]$. Proinflammatory cytokines (IL-1 $\beta$, IL18 , IFN- $\gamma$, and IL-6) are induced by excessive innate immune activation resulting from delayed or impaired early immune responses, and are key mediators of late phase hyperinflammation in COVID-19. Similar to other types of cytokine storm, this appears to be primed by decreased $\mathrm{T}$ cells and impaired $\mathrm{T}$ cell functions, and culminates in tissue damage [9॰]. Lung tissue from patients with severe COVID-19 shows hemophagocytosis, a central pathologic feature of cytokine storm [12], and an expanded inflammatory macrophage phenotype, possibly driven by IFN $-\gamma$ and TNF $\alpha$, is demonstrated in bronchoalveolar lavage of these patients [13]. Exuberant neutrophil responses with release of neutrophil extracellular traps (NET) are also implicated in lung endothelial damage in COVID-19. Affected patient sera could robustly stimulate NETosis of control neutrophils in vitro [14]. Consistent with these observations, peripheral blood lymphopenia and neutrophilia are prominent and have prognostic value in severe COVID-19 [15].
Abnormal coagulation panels and a variety of antiphospholipid (aPL) antibodies have been described in COVID-19, along with a range of thromboembolic complications occurring despite standard thromboprophylaxis $[16,17]$. Thromboses are usually venous and less commonly arterial, and can be widespread with cases of thrombotic microangiopathy (TMA), usually in the lungs [18-20]. COVID-19-related TMA involves complement and platelet activation without the extent of platelet consumption observed in diffuse intravascular coagulation (DIC) [17]. Contrary to DIC, schistocytes are absent, platelet counts are mildly decreased, and bleeding is uncommon. Pathogenesis of COVID-19-induced thrombosis appears to involve multiple mechanisms related to inflammation, including endothelial injury and dysfunction, macrophage activation, NET formation, dysregulated complement activation, and renin-aldosterone-angiotensin system (RAAS) activation [15]. The clinical relevance of the observed aPL antibodies remains under investigation [16].

\section{COVID-19 in SLE: Immunologic Implications}

Innate and adaptive immunologic perturbations prevalent in SLE may increase susceptibility to COVID-19, lead to prolonged viral shedding, or predispose to more severe disease [3, 21, 22]. In SARS-CoV-2-infected patients with SLE, underlying DNA methylation defects, potentially exacerbated by oxidative stress, could increase ACE2 expression and enhance viremia [23]. Defects in T cell-mediated cytotoxicity in patients with SLE have been associated with increased viral susceptibility, and could be particularly relevant in severe COVID-19 [24]. At the same time, the increased type I IFN signature characteristic of SLE could enhance protection at the early phases of SARS-CoV-2 infection [25]. The impact of SARS-CoV-2 on the immunologic scaffold of SLE and on lupus disease activity nonetheless remains largely unknown. Viral infections are potential triggers of flares in SLE, while viruses like EBV have been implicated in SLE pathogenesis [26]. The SLE-induced procoagulant state with predisposition to thromboembolic events [27] may be further heightened in face of COVID-19 [17]. Overall, both the short- and long-term impact of COVID-19 on SLE remains to be explored.

\section{COVID-19 Infection in Patients with SLE: Observational Studies}

Early on in the COVID-19 pandemic, observational studies employing clinical registries, patient surveys, and reviews of hospital records attempted to capture the epidemiology and clinical course of COVID-19 in SLE and other AIRDs. Despite large cumulative numbers of patients, methodologic issues (e.g., focusing on the most sick, exclusion of 
asymptomatic or mild disease, limited availability or accuracy of PCR testing) limit the assessment of incidence or severity of COVID-19 in SLE and other AIRDs.

In a telemedicine survey of 126 Italian SLE patients, 12 cases of confirmed or suspected COVID-19 were reported. Symptoms remained mild to moderate (except for one ICU admission), with a confirmed COVID-19 incidence $(2.5 \%)$ appearing increased compared to the general population [28]. In another survey of 62 Italian SLE patients, 8 reported consistent but self-resolving symptoms [29]. COVID-19 incidence was low in 225 surveyed SLE patients from Belgium, with 18 cases of infection ( 5 confirmed), 2 of them requiring hospitalization [30]. In a telephone survey of 845 SLE patients across multiple locations in India, 17 reported self-limited symptoms suggestive of COVID-19. Only 2 were tested, one of whom was positive and required hospitalization [31].

In contrast to these reports, a more severe clinical course was described in a French series of 17 SLE patients with confirmed COVID-19. Fourteen (82\%) were hospitalized, 7 were admitted to ICU, and 2 (14\%) died [32]. SLE was quiescent in all patients except one, but comorbidities were high, with obesity and chronic kidney disease in 10 and 8 patients, respectively. Similarly, 4 out of 5 SLE patients with COVID19 from Michigan were admitted to the hospital, $3(60 \%)$ required invasive ventilation, and one died [33].

Among 16 (4\%) patients with SLE and confirmed or suspected COVID-19 from the Columbia Lupus Cohort, 7 were hospitalized and 3 developed respiratory failure [34]. In another study of 226 SLE patients from New York City, 41 developed COVID-19 confirmed by PCR (remaining were asymptomatic, or symptomatic with negative or no testing) [35•]. Among them, 24 (58\%) were hospitalized, 4 required intensive care, and 4 died. In exploratory regression analysis (due to small sample size), non-white race, presence of at least one comorbidity, and BMI were independent predictors of hospitalization [35•]. Two $(8.3 \%)$ of the hospitalized patients developed micro- and macro-thrombotic events, raising awareness for this complication in SLE. Among 85 SLE patients with COVID-19 (suspected or confirmed) in the COVID-19 Global Rheumatology Alliance registry (C19GRA), 45 (56\%) required hospitalization versus $46 \%$ of the entire C19-GRA cohort [36•]. Association of SLE with hospitalization was nonsignificant after adjusting for age and comorbidities. Results in other AIRD cohorts, some including few patients with SLE, have been consistent [37-46, 47•].

\section{Health Disparities Amidst COVID-19 and Relevance to SLE}

Data from public health departments across the USA highlight an increased incidence of COVID-19 in racial minorities, like African Americans, Hispanics, and American Indians [48].
This has been attributed to a disproportionate burden upon minorities of comorbidities like hypertension, cardiovascular disease, chronic lung disease, and kidney disease that are independently associated with incidence and severity of COVID-19 [4, 5]. It is furthermore likely that socioeconomic disadvantages prevalent in minority populations may prohibit adherence to social distancing guidelines (for reasons like employment in public-facing occupations, crowded or unstable living situations and financial constraints) or access to telemedicine [49].

Racial minority populations that are highly burdened by COVID-19 are also more frequently affected by severe SLE. Indeed, African Americans were overrepresented compared to the general population in series of COVID-19-affected SLE patients from Michigan [33], with similar results demonstrated in SLE cohorts from New York City [35•] and in AIRD patients from Massachusetts [47•]. Health disparities remain pronounced in SLE, with more severe disease, increased end organ damage, and higher mortality in racial/ethnic minorities and individuals of lower socioeconomic status [50-52]. Limited or fragmented access to subspecialty care, suboptimal prescribing and adherence to medications and delayed or limited use of standard-of-care immune suppressive therapy have been implicated, along with reliance on chronic glucocorticoid use for disease control [49]. In lupus patients, comorbidities associated with COVID-19 severity can often be traced to SLE-induced organ damage (e.g., chronic kidney disease due to lupus nephritis) and side effects of medications (e.g., steroid-induced obesity and diabetes).

\section{Immune Suppressive Treatments for SLE and COVID-19}

Early on during the COVID-19 pandemic, concerns were raised about immune suppressive therapies increasing susceptibility and severity of COVID-19. At the same time, protective effects of certain drugs were postulated by inhibiting viral entry and replication (antimalarials, mycophenolate mofetil (MMF), cyclosporine) or by dampening hyperinflammation at late stages of COVID-19 (janus kinase (JAK) inhibitors, IL-1 and IL-6 inhibitors) [2, 53, 54].

In the early days of the pandemic, publicity was drawn on hydroxychloroquine (HCQ) for treatment of COVID-19, based on in vitro studies and preliminary open label clinical trials [6]. Despite little supportive data, a wave of overprescribing resulted in supply chain issues and drug shortage, concerning for SLE patients relying on HCQ for disease control [55, 56]. HCQ remains the cornerstone of therapy in patients with SLE, associated with decreased risk of flare, reduced longer-term morbidity and mortality, and improved pregnancy outcomes [57]. Supply issues of HCQ for SLE patient have since luckily resolved, following clinical trials in hospitalized COVID-19 patients, including a randomized controlled trial and three large observational 
studies, that failed to demonstrate benefit [58]. Furthermore, HCQ use in combination with azithromycin was associated with increased mortality due to cardiac arrhythmias in this population $[58,59]$. Congruent to those results, observational studies in patients with SLE and other AIRDs and concurrent COVID-19 did not support a protective effect of HCQ against COVID-19 infection or hospitalization $[28,30,32,35 \bullet, 40,45,47 \cdot, 60,61]$. It still remains to be investigated whether antimalarials may have a role for prophylaxis against COVID-19 in high-risk individuals [59], or in thromboprophylaxis during COVID-19.

Steroids are extensively prescribed for acute management of SLE, as well as long-term in a substantial number of lupus patients. Amidst the COVID-19 pandemic, concerns were raised on corticosteroids increasing the risk and severity of COVID-19 by means of their broad immune suppressive actions and by prolonging viral shedding [62]. Besides a series of 18 patients with confirmed or suspected COVID-19 where prednisone dose was associated with positive SARS-CoV-2 PCR [30], data in SLE have been limited. Notwithstanding, in AIRD patients (14\% SLE) with COVID-19 from the C19GRA registry, prednisone-equivalent doses $\geq 10 \mathrm{mg} /$ day were associated with higher odds of hospitalization $(\mathrm{OR}=2.05, p=$ 0.03 ) [36 ]. In 103 non-SLE patients with inflammatory arthritis and COVID-19, those on oral glucocorticoids had a higher likelihood of hospital admission $(p=0.001)$ after adjustment for BMI and comorbidities [45]. The relative contribution in patients with SLE of a direct effect of corticosteroids on viral physiology and host immune responses versus a steroid-heightened risk of cardiovascular disease and diabetes versus confounding by social determinants of health (i.e., poor access to care) remains open to further research. Based on those studies, the American College of Rheumatology (ACR) task force endorsed continuation of standard-of-care glucocorticoid administration, with avoidance of abrupt treatment withdrawal, along with utilization of the minimum effective dose and for minimum duration of time [63•]. Besides treatment of the underlying disease, a role of steroids in COVID-19-induced inflammation has been extensively explored. Retrospective studies suggested lack of benefit, and potential for harm of corticosteroids in hospitalized COVID19 patients that are less sick or very early in the disease course (e.g., not requiring supplemental oxygen) [64]. Emerging data however support corticosteroid use in hypoxemic patients with COVID-19 and in the late phase of infection characterized by hyperinflammation and cytokine storm [65].

Conventional synthetic disease modifying anti-rheumatic drugs (csDMARDs) like methotrexate, sulfasalazine, and leflunomide are routinely prescribed for lupus arthritis, mucocutaneous, and pleuropulmonary disease, whereas MMF and azathioprine are reserved for resistant manifestations, renal and hematologic disease, and tacrolimus and cyclosporine are used as 2nd- or 3rd-line treatment. A number of studies have examined associations of csDMARDs and severe
COVID-19 in SLE and other AIRDs. Among 41 SLE patients with confirmed COVID-19 from New York City, use of immune suppressants (csDMARDs and biologics combined) was not associated with hospitalizations [35•]. In series of 18 SLE patients from New York City with confirmed or presumed COVID-19, intake of immune suppressants before admission did not seem to influence the severity of infection [34]. Use of csDMARDs, alone or in combination with biologic and targeted synthetic DMARDs (b/tsDMARDs), prior to COVID-19 diagnosis, was similarly not associated with hospitalizations in AIRD patients from C19-GRA [36•]. Observations in other AIRD cohorts have been consistent $[30,40,43,45]$. Similarly, in patients with solid organ transplants on chronic immune suppression, no difference in exposure to csDMARDs could be shown in patients with mild versus severe COVID-19 [66].

In addition to FDA-approved belimumab, a number of biologics (bDMARDs) and targeted synthetic DMARDs (tsDAMRDs) are used off label in SLE. Evidence of their safety during COVID-19 remains sporadic, derived from cohorts with other AIRDs [40-42], or extrapolated from other infections. With paucity of COVID-19 specific data, assessment of belimumab risk rests entirely on previous reports of an overall benign safety profile [67]. Similarly, decision-making on use of abatacept during COVID-19 relies on older studies in patients with rheumatoid arthritis not showing increased risk of infection compared to other biologics [68]. Data on rituximab during COVID-19 refer to patients with granulomatosis with polyangiitis reporting severe COVID-19 [69, 70], but also mild disease clearing in the absence of antiviral antibodies [71]. Rituximab selectively eliminates B cells [71], not affecting innate immunity and mildly suppressing $\mathrm{T}$ cell responses considered important in early defense against SARSCoV-2 [10]. Severe infections after rituximab were notably associated with concurrent steroid use in older reports [72]. Beyond any controversy on COVID-19 risk, blunting of immunologic response to an anticipated SARS-CoV-2 vaccine by rituximab-induced $\mathrm{B}$ cell depletion remains a concern [73]. JAK inhibitors (JAKi) and rarely TNF inhibitors (TNFi) are used off label in treatment of SLE. In 103 patients with rheumatoid arthritis or spondylarthritis from New York City $(60 \%$ on a biologic, $11 \%$ on JAKi), JAKi use was associated with increased hospitalizations in multivariate analysis (OR 10.23, $P=0.007$ ) [45]. Four deaths occurred in patients with other risk factors, one of them on TNFi while none on JAKi [45]. In AIRD patients (39\% on biologics or JAKi) with COVID-19 from C19-GRA, biologics or JAKi were associated with lower odds of hospitalization, largely driven by TNFi (OR 0.46, $p=$ 0.03 ) [36•]. Caution on causal inference was advised by authors of both studies, due to small numbers of patients and significant potential for residual confounding.

Although data remain limited to allow conclusions on specific agents, no association has thus far become evident 
between immunosuppressive drug use and severe COVID-19 with a likely exception of corticosteroids [74]. Guidelines by the ACR and the European League against Rheumatism (EULAR) support the continued use of $\mathrm{cs} / \mathrm{b} / \mathrm{tsDMARDs}$ in the absence of exposure to SARS-CoV-2 and confirmed or suspected COVID-19 infection [63•, 75]. Notably, ACR recommendations on JAKi use during COVID-19 have been more guarded, due to concerns of dampening innate antiviral pathways by their broad immune suppressive effect [63•]. Biologics targeting IL-1 and IL-6 signaling may have a role in treatment of hyperinflammation associated with severe COVID-19 [9•, 11], but research is ongoing. Continuation of IL-6 inhibitors after SARS-CoV-2 exposure or infection was endorsed by the ACR on a case-by-case basis; nonetheless, it remains unclear if these drugs are safer compared to other biologics in early stages of COVID-19. Off-label use of these drugs in SLE however remains sporadic. In the setting of severe COVID-19 with TMA, anticoagulation and corticosteroids, IVIG therapy, plasma exchange, and therapies targeting complement activation are being increasingly explored [17]. Regarding ACE inhibitors and angiotensin receptor blockers, concerns have been raised about increasing levels of ACE2 and possibly susceptibility to infection [7], but clinical data have been insufficient to support beneficial or detrimental effects, and recommendations continue to support their standard of care use in patients with SLE [63॰].

\section{Conclusions}

The multifaceted relation of COVID-19 with SLE has been a matter of ongoing research, with an agenda spanning from the immunologic interplay of SARS-CoV-2 and the SLE host to the role of comorbidities, socio-demographic factors, and immune suppressive treatments. Data on COVID-19 in patients with SLE nevertheless remain limited, mostly derived from case reports, case series, and registries with many potential sources for bias, or extrapolated from other AIRDs. With those limitations in mind, it is difficult to ascertain from currently available patient data if SLE per se will be a significant risk factor for contracting COVID-19 or developing poor subsequent outcomes. Immune suppressive medications beyond steroids do not appear to increase the risk or severity of COVID-19 infection, although more data on specific medications are needed. On the contrary, such risks were heightened by high-risk exposures to SARS-CoV-2, concomitant corticosteroids, and comorbidities. Overall, consensus guidelines by the ACR and EULAR recommend immune suppressive medications to be continued and steroids minimized in patients with SLE in the absence of confirmed or suspected COVID19 infection. The rapidly evolving landscape of COVID-19 research does not however favor firm and durable conclusions. Meanwhile, maintaining disease remission in SLE patients continues to be key to preventing SLE complications, hospitalization, and risk of exposure to COVID-19. While awaiting more comprehensive studies, our focus will remain on sound clinical practice, individualized decision-making, and adherence to general preventive measures in caring for patients with SLE amidst the pandemic.

\section{Compliance with Ethical Standards}

Conflict of Interest The authors declare that they have no conflicts of interest.

Human and Animal Rights and Informed Consent This article does not contain any studies with animal subjects performed by the authors. For referenced studies with human or animal subjects coauthored by Dr. Sawalha, compliance with ethical guidelines is addressed in the corresponding manuscripts.

\section{References}

Papers of particular interest, published recently, have been highlighted as:

\section{- Of importance}

1. Kaul A, Gordon C, Crow MK, Touma Z, Urowitz MB, van Vollenhoven R, et al. Systemic lupus erythematosus. Na Rev Dis Primers. 2016;2:16039. https://doi.org/10.1038/nrdp.2016.39.

2. Felsenstein S, Herbert JA, McNamara PS, Hedrich CM. COVID19: immunology and treatment options. Clin Immunol. 2020;215: 108448. https://doi.org/10.1016/j.clim.2020.108448.

3. Danza A, Ruiz-Irastorza G. Infection risk in systemic lupus erythematosus patients: susceptibility factors and preventive strategies. Lupus. 2013;22(12):1286-94. https://doi.org/10.1177/ 0961203313493032.

4. Petrilli CM, Jones SA, Yang J, Rajagopalan H, O'Donnell L, Chernyak Y, et al. Factors associated with hospital admission and critical illness among 5279 people with coronavirus disease 2019 in New York City: prospective cohort study. BMJ. 2020;369:m1966. https://doi.org/10.1136/bmj.m1966.

5. Docherty AB, Harrison EM, Green CA, Hardwick HE, Pius R, Norman L, et al. Features of 20133 UK patients in hospital with covid-19 using the ISARIC WHO Clinical Characterisation Protocol: prospective observational cohort study. BMJ. 2020;369: m1985. https://doi.org/10.1136/bmj.m1985.

6. Vabret N, Britton GJ, Gruber C, Hegde S, Kim J, Kuksin M, et al. Immunology of COVID-19: current state of the science. Immunity. 2020;52(6):910-41. https://doi.org/10.1016/j.immuni.2020.05.002.

7. Sturrock BR, Milne KM, Chevassut TJ. The renin-angiotensin system - a therapeutic target in COVID-19? Clin Med (Lond). 2020;20(4):e72-e5. https://doi.org/10.7861/clinmed.2020-0146.

8. Pascarella G, Strumia A, Piliego C, Bruno F, Del Buono R, Costa F, et al. COVID-19 diagnosis and management: a comprehensive review. J Intern Med. 2020;288(2):192-206. https://doi.org/10.1111/ joim. 13091.

9. Jamilloux Y, Henry T, Belot A, Viel S, Fauter M, El Jammal T, et al. Should we stimulate or suppress immune responses in COVID-19? Cytokine and anti-cytokine interventions. Autoimmun Rev. 2020;19(7):102567. https://doi.org/10.1016/j. autrev.2020.102567 Comprehensive review of COVID-19 immunopathology. 
10. Baker D, Amor S, Kang AS, Schmierer K, Giovannoni G. The underpinning biology relating to multiple sclerosis disease modifying treatments during the COVID-19 pandemic. Mult Scler Relat Disord. 2020;43:102174. https://doi.org/10.1016/j.msard.2020. 102174.

11. Henderson LA, Canna SW, Schulert GS, Volpi S, Lee PY, Kernan $\mathrm{KF}$, et al. On the alert for cytokine storm: immunopathology in COVID-19. Arthritis Rheum. 2020;72(7):1059-63. https://doi. org/10.1002/art.41285.

12. Prilutskiy A, Kritselis M, Shevtsov A, Yambayev I, Vadlamudi C, Zhao Q, et al. SARS-CoV-2 infection-associated hemophagocytic lymphohistiocytosis. Am J Clin Pathol. 2020;154(4):466-74. https://doi.org/10.1093/ajcp/aqaa124.

13. Zhang F, Mears JR, Shakib L, Beynor JI, Shanaj S, Korsunsky I, et al. IFN- gamma and TNF- alpha drive a CXCL10 + CCL2 + macrophage phenotype expanded in severe COVID-19 and other diseases with tissue inflammation. bioRxiv. 2020. https://doi.org/ 10.1101/2020.08.05.238360.

14. Zuo Y, Yalavarthi S, Shi H, Gockman K, Zuo M, Madison JA, et al. Neutrophil extracellular traps in COVID-19. JCI Insight. 2020;5(11). https://doi.org/10.1172/jci.insight.138999.

15. Abou-Ismail MY, Diamond A, Kapoor S, Arafah Y, Nayak L. The hypercoagulable state in COVID-19: incidence, pathophysiology, and management. Thromb Res. 2020;194:101-15. https://doi.org/ 10.1016/j.thromres.2020.06.029.

16. Gkrouzman E, Barbhaiya M, Erkan D, Lockshin MD. A reality check on antiphospholipid antibodies in COVID-19-associated coagulopathy. Arthritis Rheum. 2020. https://doi.org/10.1002/art. 41472.

17. Merrill JT, Erkan D, Winakur J, James JA. Emerging evidence of a COVID-19 thrombotic syndrome has treatment implications. Nat Rev Rheumatol. 2020;16:581-9. https://doi.org/10.1038/s41584020-0474-5.

18. Bowles L, Platton S, Yartey N, Dave M, Lee K, Hart DP, et al. Lupus anticoagulant and abnormal coagulation tests in patients with Covid-19. N Engl J Med. 2020;383(3):288-90. https://doi.org/10. 1056/NEJMc2013656.

19. Devreese KMJ, Linskens EA, Benoit D, Peperstraete H. Antiphospholipid antibodies in patients with COVID-19: a relevant observation? J Thromb Haemost. 2020;18:2191-201. https://doi. org/10.1111/jth.14994.

20. Mantovani Cardoso E, Hundal J, Feterman D, Magaldi J. Concomitant new diagnosis of systemic lupus erythematosus and COVID-19 with possible antiphospholipid syndrome. Just a coincidence? A case report and review of intertwining pathophysiology. Clin Rheumatol. 2020. https://doi.org/10.1007/s10067-02005310-1.

21. Sawalha AH, Manzi S. Coronavirus Disease-2019: implication for the care and management of patients with systemic lupus erythematosus. Eur J Rheumatol. 2020;7:S117-20. https://doi.org/10. 5152/eurjrheum.2020.20055.

22. Sawalha AH. Patients with lupus are not protected from COVID19. Ann Rheum Dis. 2020:annrheumdis-2020-217656. https://doi. org/10.1136/annrheumdis-2020-217656.

23. Sawalha AH, Zhao M, Coit P, Lu Q. Epigenetic dysregulation of ACE2 and interferon-regulated genes might suggest increased COVID-19 susceptibility and severity in lupus patients. Clin Immunol. 2020;215:108410. https://doi.org/10.1016/j.clim.2020. 108410.

24. Katsuyama E, Suarez-Fueyo A, Bradley SJ, Mizui M, Marin AV, Mulki L, et al. The CD38/NAD/SIRTUIN1/EZH2 Axis mitigates cytotoxic CD8 T cell function and identifies patients with SLE prone to infections. Cell Rep. 2020;30(1):112-23 e4. https://doi. org/10.1016/j.celrep.2019.12.014.
25. Niewold TB. Interferon alpha as a primary pathogenic factor in human lupus. J Interf Cytokine Res. 2011;31(12):887-92. https:// doi.org/10.1089/jir.2011.0071.

26. James JA, Robertson JM. Lupus and Epstein-Barr. Curr Opin Rheumatol. 2012;24(4):383-8. https://doi.org/10.1097/BOR. 0b013e3283535801.

27. Pons-Estel GJ, Andreoli L, Scanzi F, Cervera R, Tincani A. The antiphospholipid syndrome in patients with systemic lupus erythematosus. J Autoimmun. 2017;76:10-20. https://doi.org/10.1016/j. jaut.2016.10.004.

28. Bozzalla Cassione E, Zanframundo G, Biglia A, Codullo V, Montecucco C, Cavagna L. COVID-19 infection in a northernItalian cohort of systemic lupus erythematosus assessed by telemedicine. Ann Rheum Dis. 2020;79:1382-3. https://doi.org/10. 1136/annrheumdis-2020-217717.

29. Favalli EG, Gerosa M, Murgo A, Caporali R. Are patients with systemic lupus erythematosus at increased risk for COVID-19? Ann Rheum Dis. 2020:annrheumdis-2020-217787. https://doi.org/ 10.1136/annrheumdis-2020-217787.

30. Gendebien Z, von Frenckell C, Ribbens C, Andre B, Thys M, Gangolf M, et al. Systematic analysis of COVID-19 infection and symptoms in a systemic lupus erythematosus population: correlation with disease characteristics, hydroxychloroquine use and immunosuppressive treatments. Ann Rheum Dis. 2020:annrheumdis2020-218244. https://doi.org/10.1136/annrheumdis-2020-218244.

31. Goyal M, Patil P, Pathak H, Santhanam S, Goel A, Sharma V, et al. Impact of COVID-19 pandemic on patients with SLE: results of a large multicentric survey from India. Ann Rheum Dis. 2020: annrheumdis-2020-218013. https://doi.org/10.1136/annrheumdis2020-218013.

32. Mathian A, Mahevas M, Rohmer J, Roumier M, Cohen-Aubart F, Amador-Borrero B, et al. Clinical course of coronavirus disease 2019 (COVID-19) in a series of 17 patients with systemic lupus erythematosus under long-term treatment with hydroxychloroquine. Ann Rheum Dis. 2020;79(6):837-9. https:// doi.org/10.1136/annrheumdis-2020-217566.

33. Wallace B, Washer L, Marder W, Kahlenberg JM. Patients with lupus with COVID-19: University of Michigan experience. Ann Rheum Dis. 2020:annrheumdis-2020-217794. https://doi.org/10. 1136/annrheumdis-2020-217794.

34. Gartshteyn Y, Askanase AD, Schmidt NM, Bernstein EJ, Khalili L, Drolet R, et al. COVID-19 and systemic lupus erythematosus: a case series. Lancet Rheumatol. 2020;2(8):e452-e4. https://doi.org/ 10.1016/s2665-9913(20)30161-2.

35. Fernandez-Ruiz R, Masson M, Kim MY, Myers B, Haberman RH, Castillo R, et al. Leveraging the United States epicenter to provide insights on COVID-19 in patients with systemic lupus erythematosus. Arthritis Rheumatol. 2020. https://doi.org/10.1002/art.41450 Prospective cohort study of systematically collected patients with SLE and confirmed or suspected COVID-19 from New York City.

36. Gianfrancesco M, Hyrich KL, Al-Adely S, Carmona L, Danila MI, Gossec L, et al. Characteristics associated with hospitalisation for COVID-19 in people with rheumatic disease: data from the COVID-19 Global Rheumatology Alliance physician-reported registry. Ann Rheum Dis. 2020;79(7):859-66. https://doi.org/10.1136/ annrheumdis-2020-217871 Compreheinsive report of $\mathbf{6 0 0}$ patients with AIRDs and confirmed or suspected COVID-19 from the Global Rheumatology Alliance Registry.

37. Monti S, Balduzzi S, Delvino P, Bellis E, Quadrelli VS, Montecucco C. Clinical course of COVID-19 in a series of patients with chronic arthritis treated with immunosuppressive targeted therapies. Ann Rheum Dis. 2020;79(5):667-8. https://doi.org/10. 1136/annrheumdis-2020-217424.

38. Favalli EG, Agape E, Caporali R. Incidence and clinical course of COVID-19 in patients with connective tissue diseases: a descriptive 
observational analysis. J Rheumatol. 2020;47(8):1296. https://doi. org/10.3899/jrheum.200507.

39. Zen M, Fuzzi E, Astorri D, Saccon F, Padoan R, Ienna L, et al. SARS-CoV-2 infection in patients with autoimmune rheumatic diseases in northeast Italy: A cross-sectional study on 916 patients. J Autoimmun. 2020;112:102502. https://doi.org/10.1016/j.jaut. 2020.102502.

40. Favalli EG, Monti S, Ingegnoli F, Balduzzi S, Caporali R, Montecucco C. Incidence of COVID-19 in patients with rheumatic diseases treated with targeted immunosuppressive drugs: what can we learn from observational data? Arthritis Rheum. 2020;72:1600 6. https://doi.org/10.1002/art.41388.

41. Salvarani C, Bajocchi G, Mancuso P, Galli E, Muratore F, Boiardi L, et al. Susceptibility and severity of COVID-19 in patients treated with bDMARDS and tsDMARDs: a population-based study. Ann Rheum Dis. 2020;79(7):986-8. https://doi.org/10.1136/ annrheumdis-2020-217903.

42. Sanchez-Piedra C, Diaz-Torne C, Manero J, Pego-Reigosa JM, Rua-Figueroa I, Gonzalez-Gay MA, et al. Clinical features and outcomes of COVID-19 in patients with rheumatic diseases treated with biological and synthetic targeted therapies. Ann Rheum Dis. 2020;79(7):988-90. https://doi.org/10.1136/annrheumdis-2020217948.

43. Freites Nuñez DD, Leon L, Mucientes A, Rodriguez-Rodriguez L, Font Urgelles J, Madrid García A, et al. Risk factors for hospital admissions related to COVID-19 in patients with autoimmune inflammatory rheumatic diseases. Ann Rheum Dis. 2020;79:1393-9. https://doi.org/10.1136/annrheumdis-2020-217984.

44. Marques C, Pinheiro MM, Reis Neto ET, Dantas AT, Ribeiro FM, Melo AKG. COVID-19 in patients with rheumatic diseases: what is the real mortality risk? Ann Rheum Dis. 2020:annrheumdis-2020218388. https://doi.org/10.1136/annrheumdis-2020-218388.

45. Haberman RH, Castillo R, Chen A, Yan D, Ramirez D, Sekar V, et al. COVID-19 in patients with inflammatory arthritis: a prospective study on the effects of comorbidities and DMARDs on clinical outcomes. Arthritis Rheum. 2020;72:1981-9. https://doi.org/10. 1002/art.41456.

46. Haberman R, Axelrad J, Chen A, Castillo R, Yan D, Izmirly P, et al. Covid-19 in immune-mediated inflammatory diseases - case series from New York. N Engl J Med. 2020;383(1):85-8. https://doi.org/ 10.1056/NEJMc2009567.

47. D'Silva KM, Serling-Boyd N, Wallwork R, Hsu T, Fu X, Gravallese EM, et al. Clinical characteristics and outcomes of patients with coronavirus disease 2019 (COVID-19) and rheumatic disease: a comparative cohort study from a US 'hot spot'. Ann Rheum Dis. 2020. https://doi.org/10.1136/annrheumdis-2020217888 Cohort study of patients with AIRD and COVID-19 matched to non-AIRD comparators from a large heathcare system in the greater Boston area.

48. Webb Hooper M, Nápoles AM, Pérez-Stable EJ. COVID-19 and racial/ethnic disparities. JAMA. 2020;323:2466-7. https://doi.org/ 10.1001/jama.2020.8598.

49. Feldman CH, Ramsey-Goldman R. Widening disparities among patients with rheumatic diseases in the COVID-19 era: an urgent call to action. Arthritis Rheum. 2020;72:1409-11. https://doi.org/ 10.1002/art.41306.

50. Feldman CH, Hiraki LT, Liu J, Fischer MA, Solomon DH, Alarcón GS, et al. Epidemiology and sociodemographics of systemic lupus erythematosus and lupus nephritis among US adults with Medicaid coverage, 2000-2004. Arthritis Rheum. 2013;65(3):753-63. https:// doi.org/10.1002/art.37795.

51. Bruce IN, O'Keeffe AG, Farewell V, Hanly JG, Manzi S, Su L, et al. Factors associated with damage accrual in patients with systemic lupus erythematosus: results from the Systemic Lupus International Collaborating Clinics (SLICC) Inception cohort.
Ann Rheum Dis. 2015;74(9):1706-13. https://doi.org/10.1136/ annrheumdis-2013-205171.

52. Gómez-Puerta JA, Barbhaiya M, Guan H, Feldman CH, Alarcón GS, Costenbader KH. Racial/ethnic variation in all-cause mortality among United States Medicaid recipients with systemic lupus erythematosus: a Hispanic and Asian paradox. Arthritis Rheum. 2015;67(3):752-60. https://doi.org/10.1002/art.38981.

53. Lai Q, Spoletini G, Bianco G, Graceffa D, Agnes S, Rossi M, et al. SARS-CoV2 and immunosuppression: a double-edged sword. Transpl Infect Dis. 2020:e13404. https://doi.org/10.1111/tid.13404.

54. Jorgensen SCJ, Tse CLY, Burry L, Dresser LD. Baricitinib: a review of pharmacology, safety, and emerging clinical experience in COVID-19. Pharmacotherapy. 2020;40(8):843-56. https://doi.org/ 10.1002/phar.2438.

55. Scheetz MH, Konig MF, Robinson PC, Sparks JA, Kim AHJ. A pharmacokinetics-informed approach to navigating hydroxychloroquine shortages in patients with rheumatic disease during the COVID-19 pandemic. ACR Open Rheumatol. 2020. https://doi.org/10.1002/acr2.11164.

56. Mendel A, Bernatsky S, Askanase A, Bae SC, Clarke AE, Costedoat-Chalumeau N, et al. Hydroxychloroquine shortages among patients with systemic lupus erythematosus during the COVID-19 pandemic: experience of the Systemic Lupus International Collaborating Clinics. Ann Rheum Dis. 2020: annrheumdis-2020-218164. https://doi.org/10.1136/annrheumdis2020-218164.

57. Ruiz-Irastorza G, Martín-Iglesias D, Soto-Peleteiro A. Update on antimalarials and systemic lupus erythematosus. Curr Opin Rheumatol. 2020;Publish Ahead of Print. https://doi.org/10.1097/ bor.0000000000000743.

58. Das RR, Jaiswal N, Dev N, Jaiswal N, Naik SS, Sankar J. Efficacy and safety of anti-malarial drugs (chloroquine and hydroxychloroquine) in treatment of COVID-19 infection: a systematic review and meta-analysis. Front Med. 2020;7:482. https://doi.org/10. 3389/fmed.2020.00482

59. Infante M, Ricordi C, Alejandro R, Caprio M, Fabbri A. Hydroxychloroquine in the COVID-19 pandemic era: in pursuit of a rational use for prophylaxis of SARS-CoV-2 infection. Expert Rev Anti-Infect Ther. 2020:1-12. https://doi.org/10.1080/ 14787210.2020.1799785.

60. Konig MF, Gianfrancesco M, Yazdany J, Robinson PC. Patients with systemic lupus erythematosus using hydroxychloroquine or chloroquine develop severe COVID-19 at similar frequency as patients not on antimalarials: need to explore antithrombotic benefits for COVID-19 coagulopathy. Response to: 'Clinical course of COVID-19 in patients with systemic lupus erythematosus under long-term treatment with hydroxychloroquine' by Carbillon et al. Ann Rheum Dis. 2020. https://doi.org/10.1136/annrheumdis-2020217990.

61. Singer ME, Kaelber DC, Antonelli MJ. Hydroxychloroquin ineffective for COVID-19 prophylaxis in lupus and rheumatoid arthritis. Ann Rheum Dis. 2020:annrheumdis-2020-218500. https://doi. org/10.1136/annrheumdis-2020-218500.

62. Xu K, Chen Y, Yuan J, Yi P, Ding C, Wu W, et al. Factors associated with prolonged viral RNA shedding in patients with coronavirus disease 2019 (COVID-19). Clin Infect Dis. 2020;71(15):799 806. https://doi.org/10.1093/cid/ciaa351.

63. Mikuls TR, Johnson SR, Fraenkel L, Arasaratnam RJ, Baden LR, Bermas BL, et al. American College of Rheumatology Guidance for the Management of Rheumatic Disease in Adult Patients During the COVID-19 Pandemic: Version 2. Arthritis Rheumatol. 2020. https://doi.org/10.1002/art.41437 Guidelines by the ACR on the management of patients with AIRDs during COVID-19.

64. Chatterjee K, Wu CP, Bhardwaj A, Siuba M. Steroids in COVID19: an overview. Cleve Clin J Med. 2020. https://doi.org/10.3949/ ccjm. 87 a.ccc059. 
65. Horby P, Lim WS, Emberson JR, Mafham M, Bell JL, Linsell L, et al. Dexamethasone in hospitalized patients with Covid-19 - preliminary report. N Engl J Med. 2020. https://doi.org/10.1056/ NEJMoa2021436.

66. Pereira MR, Mohan S, Cohen DJ, Husain SA, Dube GK, Ratner LE, et al. COVID-19 in solid organ transplant recipients: initial report from the US epicenter. Am J Transplant Off J Am Soc Transplant Am Soc Transplant Surg. 2020;20(7):1800-8. https:// doi.org/10.1111/ajt.15941.

67. Wallace DJ, Ginzler EM, Merrill JT, Furie RA, Stohl W, Chatham WW, et al. Safety and efficacy of belimumab plus standard therapy for up to thirteen years in patients with systemic lupus erythematosus. Arthritis Rheum. 2019;71(7):1125-34. https://doi.org/10.1002/ art.40861.

68. Montastruc F, Renoux C, Hudson M, Dell'Aniello S, Simon TA, Suissa S. Abatacept initiation in rheumatoid arthritis and the risk of serious infection: a population-based cohort study. Semin Arthritis Rheum. 2019;48(6):1053-8. https://doi.org/10.1016/j.semarthrit. 2019.01.009.

69. Guilpain P, Le Bihan C, Foulongne V, Taourel P, Pansu N, Maria ATJ, et al. Rituximab for granulomatosis with polyangiitis in the pandemic of covid-19: lessons from a case with severe pneumonia. Ann Rheum Dis. 2020:annrheumdis-2020-217549. https://doi.org/ 10.1136/annrheumdis-2020-217549.

70. Sharmeen S, Elghawy A, Zarlasht F, Yao Q. COVID-19 in rheumatic disease patients on immunosuppressive agents. Semin
Arthritis Rheum. 2020;50(4):680-6. https://doi.org/10.1016/j. semarthrit.2020.05.010.

71. Fallet B, Kyburz D, Walker UA. Mild course of COVID-19 and spontaneous virus clearance in a patient with depleted peripheral blood B cells due to rituximab treatment. Arthritis Rheum. 2020;72: 1581-2. https://doi.org/10.1002/art.41380.

72. Tudesq JJ, Cartron G, Rivière S, Morquin D, Iordache L, Mahr A, et al. Clinical and microbiological characteristics of the infections in patients treated with rituximab for autoimmune and/or malignant hematological disorders. Autoimmun Rev. 2018;17(2):115-24. https://doi.org/10.1016/j.autrev.2017.11.015.

73. Kado R, Sanders G, McCune WJ. Suppression of normal immune responses after treatment with rituximab. Curr Opin Rheumatol. 2016;28(3):251-8. https://doi.org/10.1097/bor. 0000000000000272 .

74. Fung M, Babik JM. COVID-19 in Immunocompromised hosts: what we know so far. Clin Infect Dis. 2020. https://doi.org/10. 1093/cid/ciaa863.

75. Landewe RB, Machado PM, Kroon F, Bijlsma HW, Burmester GR, Carmona $\mathrm{L}$, et al. EULAR provisional recommendations for the management of rheumatic and musculoskeletal diseases in the context of SARS-CoV-2. Ann Rheum Dis. 2020;79(7):851-8. https:// doi.org/10.1136/annrheumdis-2020-217877.

Publisher's Note Springer Nature remains neutral with regard to jurisdictional claims in published maps and institutional affiliations. 